\title{
MOLECULAR DISSECTION OF THE CELLULAR MECHANISMS INVOLVED IN NICKEL HYPERACCUMULATION
}

\author{
PRINCIPLE INVESTIGATOR: DAVID E. SALT
}

\author{
AWARD NUMBER: DE-FG07-98ER20295
}

\section{FINAL REPORT}

Hyperaccumulator plant species are able to accumulate between 1-5\% of their biomass as metal. However, these plants are often small, slow growing, and do not produce a high biomass. Phytoextraction, a cost-effective, in situ, plant based approach to soil remediation takes advantage of the remarkable ability of hyperaccumulating plants to concentrate metals from the soil and accumulate them in their harvestable, above-ground tissues (Salt et al., 1998). However, to make use of the valuable genetic resources identified in metal hyperaccumulating species, it will be necessary to transfer this material to high biomass rapidly growing crop plants (Persans and Salt, 2000). These plants would then be ideally suited to the phytoremediation process, having the ability to produce large amount of metal-rich plant biomass for rapid harvest and soil cleanup. Although progress is being made in understanding the genetic basis of metal hyperaccumulation (Salt and Krämer, 1999; Persans and Salt, 2000) a more complete understanding will be necessary before we can take full advantage of the genetic potential of these plants. Research funds provided by the DOE EMSP (DE-FG07-98ER20295) have been used to start to uncover the genetic processes involved in the hyperaccumulation of $\mathrm{Ni}$ in Thlaspi goesingense.

Our strategy has focused on isolating and characterizing the key genetic information needed for expression of the metal-hyperaccumulation phenotype. During the term of the grant we have determined that nickel tolerance is the key difference between the hyperaccumulator $T$. goesingense and the nonaccumulator Thlaspi arvense (Krämer et al., 1997, Salt et al., 1999). We also established that this nickel tolerance was primarily due to an enhanced ability to compartmentalize $\mathrm{Ni}$ in the leaf cell vacuoles of the hyperaccumulator (Krämer et al., 2000), and it is not due to enhanced production of free histidine (Persans et al., 1998, 1999). We have made substantial progress in determining the molecular mechanism of this enhanced vacuolar accumulation. Recently, we cloned three cDNAs from the Ni hyperaccumulator $T$ goesingense using RT-PCR, and termed them Metal Tolerance Proteins (MTP) due to their ability to confer metal tolerance when heterologously expressed in yeast (Persans et al., 2002). These $T$. goesingense MTP proteins (TgMTPs) form a novel subfamily of the cation efflux family of proteins, and are distinct from related genes in non-accumulator species including Arabidopsis thaliana genes (AtZAT, AtMTPA, AtMTPB, and AtMTPC) Thlaspi arvense (TaMTP) and Brassica juncea (BjMTP). The TgMTP's are also uniquely overexpressed in the hyperaccumulator $T$. goesingense compared to the non-accumulators $A$. thaliana, $T$. arvense, or $B$. juncea. The TgMTP genes are constitutively expressed in $T$. goesingense and expression levels are unaffected by Ni treatment. Genomic southern and PCR analyses indicates that the TgMTP proteins appear to be derived from a single gene in the $T$. goesingense genome and that the TgMTPItl, $T g M T P 1 t 2$ arise from alternate splicing of this gene. We assume that for $\mathrm{Ni}$ to be safely and efficiently compartmentalized in the vacuole in $T$. goesingense a "shuttle molecule" must exist that chaperons $\mathrm{Ni}^{2+}$ from the plasma membrane, across the cytoplasm to the vacuole. Initially we hypothesized that this compound my be free histidine, as histidine is known to chelate Ni strongly at cytoplasmic pH's. We have recently discovered that a $T$. goesingense cDNA encoding serine acetyltransferase (SAT) confers a high degree of Ni-resistance when expressed in $E$. coli (Freeman et al., 2000). Serine acetyltransferase catalyzes the biosynthesis of $O$-acetylserine from serine and acetylCoA. At present we are investigating the role of SAT in Ni hyperaccumulation in T. goesingense. Based on recent data our working hypothesis is that SAT causes the overproduction of OAS, inducing the cysteine biosynthetic pathway. An unknown intermediate in this biosynthetic pathway then chelates the $\mathrm{Ni}$ within the plant. Both genetic and biochemical evidence strongly suggests that cysteine is not involved in chelating $\mathrm{Ni}$ but rather some other nitrogen/oxygen containing ligand. We feel that further studies in progress will uncover the role of SAT and identify the Ni chelate involved in conferring Ni resistance in $T$. goesingense. Once we have established the role of the $S A T$ and $M T P$ genes in Ni hyperaccumulation we hope to use these genes to manipulate Ni accumulation in high biomass plants such as corn or Indian mustard. We also hope to modify this genetic material to allow 
the hyperaccumulation of other metals such as $\mathrm{Cd}$. However, this work is out of the scope of the present funding. Our continued efforts at using X-ray spectroscopy to investigate the in vivo speciation of metals in plants has recently given rise to a new technique for the quantitative imaging of Se in intact leaf tissue (Pickering et al., 2000). We feel that this technique will be valuable in analyzing transgenic plants, develop in the future, that over expressing genes determined to be involved in metal hyperaccumulation. During the period of the grant, the PI has also been invited to contribute to several published reviews of the phytoremediation literature (Salt, 2000; Salt and Baker, 2000; Salt, 2001a, Salt, 2001b; Guerinot and Salt, 2001 ).

\section{PUBLICTIONS}

Freeman JL, Neiman K, Persans MW, Salt DE (2000) A possible role for the enzyme serine acetyltransferase in nickel tolerance in the nickel hyperaccumulator Thlaspi goesingense. American Society of Plant Physiologists, San Diego, CA, USA; (abstract 482).

Guerinot M-L, Salt DE (2001). Fortified foods and phytoremediation: two sides of the same coin. Plant Physiology 125: 164-167.

Krämer U, Pickering IJ, Prince RC, Raskin I, Salt DE. (2000). Subcellular localization and speciation of nickel in hyperaccumulator and non-accumulator Thlaspi species. Plant Physiology 122:1343-1353.

Krämer U, Smith RD, Wenzel W, Raskin I, Salt DE (1997). The role of nickel transport and tolerance in nickel hyperaccumulation by Thlaspi goesingense Hálácsy. Plant Physiology 115: 1641-1650.

Persans M, Salt DE. (2000) Possible molecular mechanisms involved in nickel, zinc and selenium hyperaccumulation in plants. Biotechnology \& Genetic Engineering Reviews. 17: 385-409.

Persans M, Xiange Y, Patnoe JMML, Krämer U, Salt DE (1999). Molecular dissection of histidine's role in nickel hyperaccumulation in Thlaspi goesingense (Hálácsy). Plant Physiology 121: 1-10.

Persans M, Yan X, Smith R, Salt DE (1998). Cloning of two cDNA's from the Ni hyperaccumulator Thlaspi goesingense: Histidinol dehydrogenase (Accession No. AF023141) and imidazolglycerolphosphate dehydratase (Accession No. AF023140), two enzymes in the histidine biosynthetic pathway. Plant Physiology, Plant Gene Register 117: 332.

Persans MW, Nieman K, Salt DE (2001) Functional Activity and Role of Cation-Efflux Family members in Ni Hyperaccumulation in Thlaspi goesingense. Proc Natl Acad Sci USA 98: 9995-10000.

Pickering IJ, Prince RC, Salt DE, George GN (2000). Quantitative chemically-specific imaging of selenium transformation in plants. Proc Natl Acad Sci USA. 97:10717-10722.

Salt DE (2000). Phytoextraction: Present applications and future promise. In: Remediation of Hazardous Waste Contaminated Soils, $2^{\text {nd }}$ Edition, Chapter 42, DL Wise, DJ Trantolo, HI Inyang, EJ Cichon (eds.), Marcel Dekker, Inc., pp 729-744.

Salt DE, Baker AJM (2000). Phytoremediation of metals. In: Biotechnology $2^{\text {nd }}$ Edition, Vol. 11B, Chapter 20, H-J Rehm, G Reed (eds.), Wiley-VCH, pp 386-397.

Salt DE, Kato N, Krämer U, Smith RD and Raskin I (1999) The role of root exudates in nickel hyperaccumulation and tolerance in accumulator and non-accumulator species of Thlaspi. In: Phytoremediation of Contaminated Soil and Water, Terry, N., Bañuelos, G.S. (eds.), Chapter 10, CRC Press LLC, Boca Raton, FL, USA, pp 191-202.

Salt DE, Krämer U (1999). Mechanisms of metal hyperaccumulation in plants. In: Phytoremediation of Toxic Metals: Using Plants to Clean-Up the Environment, Burt D. Ensley and Ilya Raskin (eds.), Chapter 13, John Wiley \& Sons, Inc., New York, NY, USA, pp 231-246.

Salt DE, Smith RD, Raskin I (1998) Phytoremediation. Ann Rev Plant Physiol Plant Mol Biol 49: 643-668.

Salt DE. Nickel Hyperaccumulation in Thlaspi goesingense: A Scientific Travelogue (2001). In Vitro Cellular \& Developmental Biology - Plant. 37: 330-333.

Salt DE (2001) Responses and Adaptations of Plants to Heavy Metal Stress. In: Molecular Tools for the assessment of Plant Adaptation to the Environment. Malcolm J. Hawkesford \& Peter Buchner (eds.), Kluwer Academic Publishers, p159. 